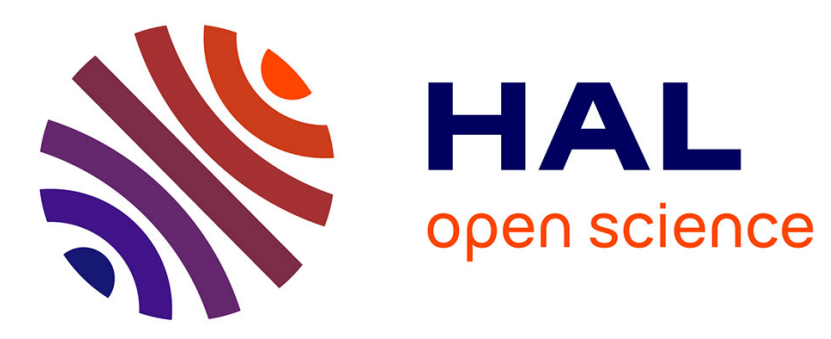

\title{
Zeros at Infinity for Infinite Dimensional Systems
}

\author{
M Malabre, Rabah Rabah
}

\section{To cite this version:}

M Malabre, Rabah Rabah. Zeros at Infinity for Infinite Dimensional Systems. Realization and Modelling in System Theory, 3, , pp.199 - 206, 1990, Progress in Systems and Control Theory 978-1-46128033-0. 10.1007/978-1-4612-3462-3_21. hal-01419626

\section{HAL Id: hal-01419626 https://hal.science/hal-01419626}

Submitted on 9 Feb 2017

HAL is a multi-disciplinary open access archive for the deposit and dissemination of scientific research documents, whether they are published or not. The documents may come from teaching and research institutions in France or abroad, or from public or private research centers.
L'archive ouverte pluridisciplinaire HAL, est destinée au dépôt et à la diffusion de documents scientifiques de niveau recherche, publiés ou non, émanant des établissements d'enseignement et de recherche français ou étrangers, des laboratoires publics ou privés. 


\title{
ZEROS AT INFINITY FOR INFINITE DIMENSIONAL SYSTEMS
}

\author{
M. MALABRE, R. RABAH
}

\begin{abstract}
The concept of zeros at infinity is generalized to some particular cases of infinite dimensional control systems : those described with bounded operators and having a finite number of inputs and outputs. These zeros are characterized with the help of four equivalent descriptions. Two geometric characterizations are provided as well as a matricial one using some particular Toeplitz matrices. The last one is directly deduced from the Structure Algorithm. Finally, for systems having a finite number of disturbance inputs, we show that the Disturbance Decoupling Problem with Measurement of the Disturbance is solvable if and only if the orders of the zeros at infinity are the same for the system with and without the disturbance. Applications to invertibility tests or to ideal observability are also given.
\end{abstract}

\section{Introduction}

It is now quite well understood that the knowledge of some particular structures is fundamental when trying to solve some control problems. For linear finite dimensional systems, this is typically the case for the structure of the zeros at infinity (see for instance [3]). Namely, regular row-by-row or block decoupling is achievable if and only if the set of the zeros at infinity of the system equals the union of those of the subsystems ([ 5], [6]...). There is a similar condition for the Disturbance Decoupling Problem with measurement of the disturbance, or equivalently for the Model Matching Problem : the disturbance can be rejected if and only if the structure of the zeros at infinity is exactly the same for the system without the disturbance and for the system with the disturbance considered as a generalized input (for the Model Matching see [ 8]). These notions of zeros at infinity have been generalized to non linear systems [11] and also described for singular linear systems [10].

The aim of this article is to show that these structural concepts and results can be extended to a new class of systems : those having a finite number of inputs and ouptuts but for which the state belongs to some infinite dimensional space. These systems are described by :

$$
\left\{\begin{array}{l}
\dot{x}(t)=A x(t)+B u(t) \\
y(t)=C x(t)
\end{array}\right.
$$

where $\mathrm{A}, \mathrm{B}$ and $\mathrm{C}$ are bounded linear operators respectively from $\mathscr{X}$ to $\mathscr{X}$, from $\mathbb{R}^{\mathrm{m}}$ to $\mathscr{X}$ and from $\mathcal{X}$ to $R P$ and $\mathscr{X}$ is a Hilbert space.

We shall first recall some basic properties and definitions for system like (1) (Section 2). We shall then generalize the famous Structure Algorithm [12] to this class of systems (Section 3). Section 4 will be mainly devoted to the different equivalent definitions for the zeros at infinity. Finally, we shall illustrate the key role of this concept by providing a new necessary and sufficient condition for the solvability of the Disturbance Decoupling Problem with measurement of the disturbance in terms of structures at infinity (Section 5). Applications to invertibility tests or to ideal (perfect) observability are also given. 


\section{Basic concepts}

We shall thus consider systems like (1) with bounded operators : $\mathrm{A} \in \mathscr{L}(\mathscr{X}), \mathrm{B} \in \mathscr{L}\left(\mathbb{R}^{\mathrm{m}}, \mathcal{X}\right)$ and $\mathrm{C} \in \mathscr{L}(\mathrm{X}, \mathbb{R} \mathrm{P})$. Since $\mathrm{A}$ is bounded, the resolvent of A can be developed as :

$$
(\lambda I-A)^{-1}=\frac{1}{\lambda} \sum_{n=0}^{\infty} \frac{A^{n}}{\lambda^{n}} \quad,|\lambda|>\|A\|
$$

Thus, (1) can also be described through its (pxm) transfer matrix :

$$
\mathrm{T}(\mathrm{s})=\mathrm{C}(\mathrm{sI}-\mathrm{A})^{-1} \mathrm{~B}=\mathrm{CB} \mathrm{s}^{-1}+\mathrm{CABs}^{-2}+\mathrm{CA}^{2} \mathrm{Bs}^{-3}+\ldots
$$

From a geometric point of view, many concepts like $(A, B)$ or $(C, A)$ invariance have known various extensions to infinite dimensional systems. Up to date references and main contributions can be found in [15].

Because of our particular assumption for A, B and C, we are in a situation where all various available definitions are actually equivalent. More precisely, there exists a supremal $(A, B)$ invariant subspace in the Kernel of $C, \mathscr{P}^{*}$, which can be obtained from the well known algorithm:

$$
\begin{aligned}
& \mathscr{V} 0=\mathscr{X}, \mathcal{V}{ }^{\mathrm{i}+1}=\operatorname{Ker} \mathrm{C} \cap \mathrm{A}^{-1}(\operatorname{ImB}+\mathcal{V} \mathrm{i}) \\
& \text { Each } \mathcal{F}^{\mathrm{i}} \text { is closed and } \mathcal{V}^{*} \text { satisfies : } \quad \mathcal{V}^{*}={ }_{\mathrm{i}}^{\infty} \stackrel{\infty}{=} \mathcal{V} \mathrm{i}
\end{aligned}
$$

In a similar way, there exists an infimal $(\mathrm{C}, \mathrm{A})$ invariant subspace containing $\operatorname{ImB} \mathcal{S}^{*}$, characterized through the following algorithm :

$$
\mathscr{S}^{0}=0, \mathscr{S}^{\mathrm{i}+1}=\operatorname{ImB}+\mathrm{A}\left(\operatorname{Ker} \mathrm{C} \cap \mathcal{S}^{\mathrm{i}}\right)
$$

Each $S^{i}$ is closed and the sequence of associated projectors, $P_{i}(\operatorname{ImP} i=S i)$, strongly converges towards a projector $\mathrm{P}^{*}$ with $\mathcal{S}^{*}=\operatorname{Im} \mathrm{P}^{*}$.

We shall also use in the sequel the following Toeplitz matrices $\Gamma_{\mathrm{i}}$ (which are (i.p $\times$ i.m)) associated with (1) or equivalently deduced from (2.2) :

$\Gamma_{\mathrm{i}}=\left[\begin{array}{ccccc}\mathrm{CB} & 0 & \cdot & \cdot & 0 \\ \mathrm{CAB} & \mathrm{CB} & 0 & \cdot & 0 \\ \cdot & \cdot & \cdot & \cdot & \dot{C} \\ \mathrm{CA}^{\mathrm{i}-1} \mathrm{~B}_{\mathrm{B}} & \mathrm{CA}^{\mathrm{i}-2 \mathrm{~B}} & \cdot & \cdot & \mathrm{CB}\end{array}\right]$

\section{3- Structure (Inversion) Algorithm}

The Structure Algorithm, as initially introduced by Silverman [12], is well known as being a very performant tool for the characterization of some geometric or structural properties of the system. This has been the case for the zeros at infinity : [13] for linear systems, [11] for affine non linear systems and [10] for singular linear systems.

We shall here generalize this kind of algonthm to systems described by (1) with $\mathrm{A} \in \mathscr{L}(\mathscr{X}), \mathrm{B} \in \mathscr{L}\left(\mathbb{R}^{\mathrm{m}}, \mathscr{X}\right)$ and $\mathrm{C} \in \mathscr{L}(\mathscr{X}, \mathbb{R P})$.

The key idea behind this algorithm is to try to recover as much information as possible on the input $u(t)$ (possibly $u(t)$ itself) starting from $y(t)$ and from some of its derivatives. This is, of course, connected to inversion problems. This algorithm works as follows : the output $\mathrm{y}=\mathrm{Cx}$ has no explicit term with $\mathrm{u}$ and has thus to be derived. After 
derivation, one has $\dot{y}=\mathrm{CAx}+\mathrm{CBu}$. Let $\mathrm{P}_{1}$ be the projector on the image of $\mathrm{CB}$. Then, let us denote :

$\left[\begin{array}{c}\mathrm{P}_{1} \\ \mathrm{I}-\mathrm{P}_{1}\end{array}\right][\mathrm{CA} \mathrm{CB}]=:\left[\begin{array}{cc}\mathrm{C}_{2} & \mathrm{D}_{2} \\ \mathrm{C}_{2} & 0\end{array}\right]$

The second stripe of this equation $\left(\mathrm{y}_{2}=\underline{\mathrm{C}}_{2} \mathrm{x}\right)$ has no $\mathrm{u}$ - term and must be derived: $\dot{y}_{2}=\underline{C}_{2} A x+\underline{C}_{2} \mathrm{Bu}$, and the algorithm goes on ; $\mathrm{P}_{2}$ being defined as the projector on Image $\left[\begin{array}{c}D_{2} \\ \underline{C}_{2} B\end{array}\right]$, we have :

$\left[\begin{array}{c}\mathrm{P}_{2} \\ \mathrm{I}-\mathrm{P}_{2}\end{array}\right]\left[\begin{array}{cc}\mathrm{C}_{2} & \mathrm{D}_{2} \\ \mathrm{C}_{2} \mathrm{~A} & \underline{\mathrm{C}}_{2} \mathrm{~B}\end{array}\right]=:\left[\begin{array}{cc}\mathrm{C}_{3} & \mathrm{D}_{3} \\ \mathrm{C}_{3} & 0\end{array}\right]$

These steps can also be written as follows (let $C_{0}=C, D_{0}=0$ and $\underline{C}_{0}=0$ ) :

At each step $k$, choose $S_{k}=\left[\begin{array}{c}P_{k} \\ I-P_{k}\end{array}\right]$, with $P_{k}$ the projector on Image $\left[\begin{array}{c}D_{k} \\ c_{k} B\end{array}\right]$, such that :

$S_{k}\left[\begin{array}{cc}C_{k} & D_{k} \\ \underline{C}_{k} A & \underline{C}_{k}^{B}\end{array}\right]=:\left[\begin{array}{cc}C_{k+1} & D_{k+1} \\ C_{k+1} & 0\end{array}\right]$

and with $D_{k+1}$ of maximal full row rank $r_{k+1}$.

We shall see in the sequel (Section 4) that, if the system (1) is of maximal rank, (that is rank $=\inf (m, p)$ ), the computation (from this algorithm) of the orders of the zeros at infinity will always be possible in a finite number of steps (this number being $n_{1}$, the supremal order of the infinite zeros). Note that, if (1) is not of maximal rank, we can always get rid of redundant inputs and outputs and restrict our attention to the part of the system which is of maximal rank. Hence, there is no loss of generality when assuming that (1) has rank equal to inf(m,p) and, in the same way, that $B$ is monic and $C$ is epic.

\section{4- Equivalent characterizations for the structure at infinity}

We shall here generalize some definitions of the zeros at infinity which are available in the case $\mathscr{X}^{\mathrm{N}} \mathbb{R}^{\mathrm{n}}([13]$, [3]). Let card $\{$.$\} denote the number of elements in \{$.$\} .$

Theorem 1 : Systems (1) of maximal rank $r=\inf (m, p)$ have $r$ infinite zeros, the orders of which $n_{1}, n_{2}, \ldots, n_{r}$ are given by $n_{i}=: \operatorname{card}\left\{p_{j} \geq i\right\}$ and where the integers $p_{i}$ 's satisfy:

$$
\begin{aligned}
\mathrm{p}_{\mathrm{i}+1} & =\operatorname{dim}\left\{\left(\operatorname{Im} \mathrm{B} \cap \mathcal{V}^{\mathrm{i}}\right) /\left(\operatorname{Im} \mathrm{B} \cap \mathcal{V}^{*}\right)\right\} & & , \forall \mathrm{i} \geq 0 \\
& =\operatorname{dim}\left(\mathrm{C}^{*} / \mathrm{C} \mathscr{S}^{\mathrm{i}}\right) & & , \forall \mathrm{i} \geq 0 \\
& =\alpha_{\max }-\alpha_{\mathrm{i}} & & , \forall \mathrm{i} \geq 0 \\
& =\rho_{\max }-\rho_{\mathrm{i}+1} & & , \forall \mathrm{i} \geq 0
\end{aligned}
$$

where :

$$
\begin{aligned}
& \alpha_{i}=: \operatorname{rank}\left(\Gamma_{i}\right)-\operatorname{rank}\left(\Gamma_{i-1}\right) \\
& \rho_{i}=: \operatorname{rank}\left(D_{i}\right),
\end{aligned}
$$

with $\alpha_{0}=0, \Gamma_{0}=0, \Gamma_{\mathrm{i}}$ defined through (2.6) and $\mathrm{D}_{\mathrm{i}}$ extracted from the Structure Algorithm (see (3.3)).

Remark : According to (2.2) and to finite dimensionality of the output and input spaces, the orders $n_{i}$ 's are finite integers. Note also that $p_{i}=\operatorname{card}\left\{n_{j} \geq i\right\}$.

Proof of Theorem 1:i): Consider $(4.1) \Leftrightarrow$ (4.3): It is easy to show, from the very definitions of $\mathcal{Q}^{\mathrm{i}}$ and $\Gamma_{\mathrm{i}}$, that for all $\mathrm{i} \geq 0$ :

$\operatorname{Im} \mathrm{B} \cap \mathcal{P} \mathbf{i}=[\mathrm{B} 0 \ldots 0] \operatorname{Ker} \Gamma_{\mathbf{i}}$.

Since B is monic, and because of the form of $\Gamma_{i}$ 's, (recall (2.6)), we have : 
$\operatorname{dim}\left(\operatorname{Im} B \cap \mathcal{V}^{\mathbf{i}}\right)=\operatorname{dim}\left(\operatorname{Ker} \Gamma_{\mathbf{i}}\right)-\operatorname{dim}\left(\operatorname{Ker} \Gamma_{\mathbf{i}-1}\right)$. Thus :

$\operatorname{dim}\left(\operatorname{Im} B \cap \mathcal{V}^{\mathrm{i}}\right)=\left(\mathrm{im}-\operatorname{rank} \Gamma_{\mathrm{i}}\right)-\left((\mathrm{i}-1) \mathrm{m}-\operatorname{rank} \Gamma_{\mathrm{i}-1}\right)=\mathrm{m}-\alpha_{\mathrm{i}}$. This implies :

$\alpha_{\max }=m-\inf \left\{\operatorname{dim}\left(\operatorname{Im} B \cap \mathcal{V}^{\mathrm{i}}\right)\right\}=\mathrm{m}-\operatorname{dim}\left(\operatorname{Im} B \cap \mathcal{V}^{*}\right)$ and, finally $:$

$\operatorname{dim}\left\{\left(\operatorname{Im} B \cap \mathcal{V}^{\mathrm{i}}\right) /\left(\operatorname{ImB} \cap \mathcal{V}^{*}\right)\right\}=\alpha_{\max }-\alpha_{\mathrm{i}} \quad, \forall \mathrm{i} \geq 0$.

ii) : Consider (4.2) $\Leftrightarrow(4.3)$ : Starting from the very definition of $\mathcal{I}$ 's (see (2.5)), it is quite easy to show that (see for instance [9]) :

$\mathrm{C} \mathscr{S}^{\mathrm{i}}=\left[\mathrm{CA}^{\mathrm{i}-1 \mathrm{~B}} \vdots \ldots \ldots . \mathrm{CAB} \vdots \mathrm{CB}\right] \operatorname{Ker}\left[\Gamma_{\mathrm{i}-1} \vdots \mathrm{O}\right] \quad \forall \mathrm{i} \geq 2$

This implies $: \operatorname{dim}\left(\mathrm{C}^{\mathrm{S}} \mathrm{i}\right)=\operatorname{dim}\left\{\operatorname{Ker}\left[\Gamma_{\mathrm{i}-1} \vdots \mathrm{O}\right]\right\}-\operatorname{dim}\left\{\operatorname{Ker}\left[\Gamma_{\mathrm{i}-1} \vdots \mathrm{O}\right] \cap \operatorname{Ker}\left[\mathrm{CA}^{\mathrm{i}-1 \mathrm{~B}}: \ldots \ldots . \mathrm{CAB} \vdots \mathrm{CB}\right]\right\}$, which, in view of the definition of $\Gamma_{i}$ 's (see (2.6)), amounts to, for all $i \geq 2$ :

$$
\begin{aligned}
\operatorname{dim}\left(\mathrm{C}^{\mathrm{i}}\right)= & \operatorname{dim}\left\{\operatorname{Ker}\left[\Gamma_{\mathrm{i}-1} \vdots \mathrm{O}\right]\right\}-\operatorname{dim}\left(\operatorname{Ker} \Gamma_{\mathrm{i}}\right)=\mathrm{m}+\operatorname{dim}\left(\operatorname{Ker}\left(\Gamma_{\mathrm{i}-1}\right)\right)-\operatorname{dim}\left(\operatorname{Ker} \Gamma_{\mathrm{i}}\right) \\
& =\operatorname{rank} \Gamma_{\mathrm{i}}-\operatorname{rank} \Gamma_{\mathrm{i}-1}=: \alpha_{\mathrm{i}} .
\end{aligned}
$$

Since this is also obviously true for $\mathrm{i}=0$ and $\mathrm{i}=1$, one has :

$$
\operatorname{dim}\left(C S^{i}\right)=\alpha_{i} \quad, \forall i \geq 0
$$

hence $\operatorname{dim}\left(C S^{*}\right)=\alpha_{\max }$, which immediately proves the equality

$\operatorname{dim}\left(C S^{*} / C S^{i}\right)=\alpha_{\max }-\alpha_{i}, \forall i \geq 0$.

iii) (4.3) $\Leftrightarrow(4.4)$ For this, it is sufficient to prove that $\alpha_{i}=\rho_{i+1}$, $\forall \mathrm{i} \geq 0$. This, in turn, is equivalent to : $\sum_{j=0}^{i} \alpha_{j}=\sum_{j=0}^{i} \rho_{j+1}, \forall i \geq 0$, otherwise written :

$$
\operatorname{rank} \Gamma_{i}=\sum_{j=0}^{i} \rho_{j+1} \quad, \forall i \geq 0
$$

This can be proved by induction. We shall only sketch here the first steps. (For this recall in particular (2.6) and (3.3) and remember that $D_{k}$ is epic for all $k \geq 1$ ) :

$* \operatorname{rank}\left(\Gamma_{0}\right)=0=\rho_{1}$

${ }^{*} \operatorname{rank}\left(\Gamma_{1}\right)=: \operatorname{rank}(C B)=\operatorname{rank}\left(D_{2}\right)=\rho_{2}+\rho_{1}$

* $\operatorname{rank}\left(\Gamma_{2}\right)=\operatorname{rank}\left[\begin{array}{cl}\mathrm{CB} & 0 \\ \mathrm{CAB} & \mathrm{CB}\end{array}\right]=\operatorname{rank}\left\{\left[\begin{array}{cc}\mathrm{S}_{1} & 0 \\ 0 & \mathrm{~S}_{1}\end{array}\right] \cdot\left[\begin{array}{cl}\mathrm{CB} & 0 \\ \mathrm{CAB} & \mathrm{CB}\end{array}\right]\right\}=\operatorname{rank}\left[\begin{array}{cc}\mathrm{D}_{2} & 0 \\ 0 & 0 \\ \mathrm{C}_{2} \mathrm{~B} & \mathrm{D}_{2} \\ \mathrm{C}_{2} \mathrm{~B} & 0\end{array}\right]$

$$
\begin{aligned}
& =\operatorname{rank}\left[\begin{array}{c}
D_{2} \\
C_{2} B
\end{array}\right]+\operatorname{rank}\left(D_{2}\right) \quad\left(\text { since } D_{2} \text { is epic }\right) \\
& =\operatorname{rank}\left(D_{3}\right)+\operatorname{rank}\left(D_{2}\right)=\rho_{3}+\rho_{2}+\rho_{1} \ldots
\end{aligned}
$$

This ends the proof of Theorem 1

It is also possible, from the Structure Algorithm, to generalize a very interesting geometric result stated by Silverman [12] and extended in [7] to singular linear systems :

Proposition 1 : The steps $\mathcal{V}^{\mathrm{i}}$ of algorithm (2.3) satisfy :

$$
\mathcal{Q i}^{\mathrm{i}}=\operatorname{Ker}\left[\begin{array}{c}
\underline{\mathrm{C}}_{0} \\
\underline{\mathrm{C}}_{1} \\
\vdots \\
\underline{\mathrm{C}}_{\mathrm{j}}
\end{array}\right]
$$$$
\forall \mathrm{i} \geq 0
$$

The proof can easily be done by induction. We shall only sketch here the first steps. 
- $\mathscr{P} 0=\mathscr{X}=\operatorname{Ker} \underline{C}_{0} \quad$ since $\underline{C}_{0}=0$

- $\mathcal{V}^{1}=\operatorname{Ker} \mathrm{C}=\operatorname{Ker} \underline{\mathrm{C}}_{1}=\operatorname{Ker}\left[\begin{array}{l}\mathrm{C}_{0} \\ \underline{C}_{1}\end{array}\right]$, since $\underline{\mathrm{C}}_{1}=\mathrm{C}$

- $\mathcal{V}^{2}=: \operatorname{Ker} \mathrm{C} \cap \mathrm{A}^{-1}\left(\operatorname{ImB}+\mathcal{P}^{1}\right)$

i) first show that $\mathscr{V}^{2} \subset \operatorname{Ker} \underline{C}_{1} \cap \operatorname{Ker} \underline{C}_{2}$ :

Since $\mathcal{P}^{2} \subset \operatorname{Ker} C=\operatorname{Ker} \underline{C}_{1}$, this amounts to $\mathcal{V P}^{2} \subset \operatorname{Ker} \underline{C}_{2}$. Now, recall that (see (3.1)): $\quad \underline{C}_{2}=:\left(I-P_{1}\right) \underline{C}_{1} A=\left(I-P_{1}\right) C A$.

Thus : $\mathrm{C}_{2} \mathcal{V}^{2} \mathrm{C}\left(\mathrm{I}-\mathrm{P}_{1}\right) \mathrm{CA} \mathrm{A}^{-1}\left(\operatorname{ImB}+\mathcal{V}^{1}\right) \subset\left(\mathrm{I}-\mathrm{P}_{1}\right) \mathrm{C}\left(\operatorname{ImB}+\mathcal{V}^{1}\right)=0$, since $C \mathcal{V}^{1}=0$ and $\left(I-P_{1}\right) C B=0($ see $(3.1))$.

ii) Let us now show the reverse inclusion :

Let $\mathrm{x} \in \operatorname{Ker} \underline{\mathrm{C}}_{1} \cap \operatorname{Ker} \underline{\mathrm{C}}_{2}$, that is :

$\mathrm{x} \in \operatorname{Ker} \mathrm{C}$

and $\left(\mathrm{I}-\mathrm{P}_{1}\right) \mathrm{CAx}=0$

This implies : $\mathrm{CAx} \in \operatorname{Ker}\left(\mathrm{I}-\mathrm{P}_{\mathcal{A}}\right)=\operatorname{Im} \mathrm{CB}$. That is $\mathrm{Ax} \in \operatorname{ImB}+\operatorname{KerC}$, which, when combined with (4.11), gives $x \in \operatorname{Ker} C \cap A^{-1}(\operatorname{ImB}+\operatorname{Ker} C)=: \mathscr{V}^{2} \ldots$ This ends the sketch of the proof of the Proposition 1

We are now able to show the deep interest of this concept of zeros at infinity, in generalizing to this class of infinite dimensional systems results available for $\mathscr{X}=\mathbb{R} n$.

\section{5 - New insights into Disturbance Decoupling Problem. Invertibility and Ideal Observability}

The Disturbance Decoupling Problem is undoubtedly the most famous example showing the interest of the so-called geometric approach ([1], [14]). This problem has also been analyzed within its different versions for infinite dimensional systems (see [4], [15]). We shall consider here the Disturbance Decoupling Problem with Measurement of the Disturbance ; more precisely, the setting is the following :

consider an infinite dimensional system with bounded operators and having a finite number of inputs $(\mathrm{u})$, disturbances $(\mathrm{q})$ and outputs $(\mathrm{y})$ described by :

$$
\left\{\begin{array}{l}
\dot{x}(t)=A x(t)+B u(t)+E q(t) \\
y(t)=C x(t)
\end{array}\right.
$$

with $\mathrm{A} \in \mathscr{L}(\mathscr{X}), \mathrm{B} \in \mathscr{L}\left(\mathbb{R}^{\mathrm{m}}, \mathscr{X}\right), \mathrm{E} \in \mathscr{L}(\mathbb{R} \mathrm{q}, \mathscr{X})$ and $\mathrm{C} \in \mathscr{L}(\mathscr{X}, \mathbb{R} \mathrm{p})$ and where $\mathscr{X}$ is a Hilbert space.

Find conditions under which there exists a state feedback law, $\mathrm{u}=\mathrm{Fx}+\mathrm{Gq}$, such that, for the closed loop system, the disturbance q has no action at all on the output $\mathrm{y}$.

This problem has been given a solution by Curtain [4], and, in our very particular situation, its solvability can be expressed as follows :

Proposition 2 [ 4] : Systems like (5.1) can be disturbance decoupled with measurement of the disturbance if and only if :

$$
\operatorname{Im} \mathrm{E} \subset \operatorname{Im} \mathrm{B}+\mathcal{P}^{*}
$$

with, as before, $\mathcal{V}^{*}$ given by $(2.4)$ and being the supremal $(\mathrm{A}, \mathrm{B})$ invariant subspace in Ker C. 
We are now able to provide an equivalent structural condition in terms of zeros at infinity which is an extension of a similar result obtained for the Model Matching Problem [ 8] when $\mathscr{X}=\mathbb{R} \mathrm{n}$.

For that, let us introduce some notation. $S^{\mathrm{i}}$ and $S_{\mathrm{e}}^{\mathrm{i}}$ will be described by the following algorithms (see (2.5)) :

$$
\mathscr{S}^{0}=0, \S^{\mathrm{i}+1}=\operatorname{Im} \mathrm{B}+\mathrm{A}\left(\operatorname{Ker} \mathrm{C} \cap \mathcal{S}^{\mathrm{i}}\right) \quad \text {, with associated limit } \mathcal{S}^{*}
$$

and similary :

$$
S_{\mathrm{e}}^{0}=0, S_{\mathrm{e}}^{\mathrm{i}+1}=\operatorname{Im}[\mathrm{B}: \mathrm{E}]+\mathrm{A}\left(\operatorname{Ker} \mathrm{C} \cap \mathcal{S}_{\mathrm{e}}^{\mathrm{i}}\right) \text {, with associated limit } \mathcal{S}_{\mathrm{e}}^{*}
$$

The structure of the zeros at infinity we shall deal with are those of system $(\mathrm{C}, \mathrm{A}, \mathrm{B})$ and $(\mathrm{C}, \mathrm{A},[\mathrm{B}: \mathrm{E}])$, respectively denoted by :

$$
\begin{array}{ll}
\mathrm{p}_{\mathrm{i}+1}=\operatorname{dim}\left(\mathrm{C}^{*} / \mathrm{C} S^{\mathrm{i}}\right) & , \forall \mathrm{i} \geq 0 \\
\mathrm{p}_{\mathrm{e} i+1}=\operatorname{dim}\left(C S_{\mathrm{e}}^{*} / \mathrm{C} \mathscr{e}_{\mathrm{e}}^{\mathrm{i}}\right) & , \forall \mathrm{i} \geq 0
\end{array}
$$

Theorem 2 : Systems like (5.2) can be disturbance decoupled with measurement of the disturbance if and only if :

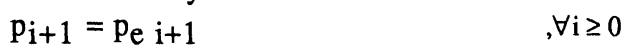

Proof : Remark first that, because $\mathcal{V}^{*}=\stackrel{\bigcap}{\mathrm{T}}=0^{\infty} \mathcal{F}^{\mathrm{i}}$, condition (5.2) :

$\operatorname{Im} \mathrm{E} \subset \operatorname{Im} \mathrm{B}+\mathcal{V}^{*}$ is equivalent to :

$$
\operatorname{Im} \mathrm{E} \subset \operatorname{Im} \mathrm{B}+\mathcal{V} \mathrm{i} \quad, \forall \mathrm{i} \geq 0
$$

i) Necessity : Assume that (5.2) is satisfied. We shall prove by induction that :

$$
\mathrm{C} \mathscr{S}_{\mathrm{e}}^{\mathrm{i}}=\mathrm{C} \mathscr{S}^{\mathrm{i}} \quad, \forall \mathrm{i} \geq 0
$$

First remark that the following is obvious :

$$
\mathcal{S}^{\mathrm{i}} \subset \mathcal{S}_{\mathrm{e}}^{\mathrm{i}} \quad, \forall \mathrm{i} \geq 0
$$

To prove (5.9), we shall thus show by induction, that :

Indeed :

$$
\mathcal{S}_{\mathrm{e}}^{\mathrm{i}} \subset \mathcal{V}^{*}+\mathcal{S}^{\mathrm{i}}, \forall \mathrm{i} \geq 0
$$

$$
\begin{aligned}
\mathscr{S}_{\mathrm{e}}^{\mathrm{i}+1}= & \operatorname{Im}[\mathrm{B}: \mathrm{E}]+\mathrm{A}\left(\operatorname{Ker} \mathrm{C} \cap \mathcal{S}_{\mathrm{e}}^{\mathrm{i}}\right) \subset \operatorname{ImB}+\operatorname{ImE}+\mathrm{A}\left(\operatorname{KerC} \cap \mathcal{S}^{\mathrm{i}}+\mathcal{V}^{*}\right) \\
& \subset \operatorname{ImB}+\operatorname{ImE}+\mathrm{A}\left(\operatorname{KerC} \cap \mathcal{S}^{\mathrm{i}}\right)+\mathcal{V}^{*} \\
& \subset \operatorname{ImB}+\mathcal{V}^{*}+\mathrm{A}\left(\operatorname{Ker} C \cap \mathcal{S}^{\mathrm{i}}\right), \text { because of }(5.2) \\
= & \mathcal{V}^{*}+\mathcal{S}^{\mathrm{i}},
\end{aligned}
$$

which ends the necessity part of the proof $\diamond$.

ii) Sufficiency The easiest way to establish sufficiency is to use the structure algorithm and the fact that $\mathrm{p}_{i}$ 's and $\mathrm{p}_{\mathrm{e}} \mathrm{i}$ 's have other equivalent characterizations (see Theorem 1) and more precisely that given by (4.4).

For that, imagine that you are performing the structure algorithm both on $(\mathrm{C}, \mathrm{A}, \mathrm{B})$ and on (C,A, $[B \vdots E])$. This will induce particular matrices $D_{i}$ and $D_{e i}($ see (3.3)) and denoting :

$$
\begin{array}{ll}
\rho_{\mathrm{i}}=\operatorname{rank}\left(D_{\mathrm{i}}\right) & , \forall \mathrm{i} \geq 0 \\
\rho_{\mathrm{ei}}=\operatorname{rank}\left(D_{\mathrm{ei}}\right) & , \forall \mathrm{i} \geq 0
\end{array}
$$


we immediately see that our hypothesis, that is :

$$
\mathrm{p}_{\mathrm{i}+1}=\mathrm{p}_{\mathrm{e} i+1} \quad, \forall \mathrm{i} \geq 0
$$

is equivalent to :

$$
\rho_{\mathrm{i}}=\rho_{\mathrm{ei}} \quad, \forall \mathrm{i} \geq 0
$$

On the other hand, because of Proposition 1, the desired result (5.8) is equivalent to :

$$
\operatorname{Im}\left\{\Phi_{i}[B \vdots E]\right\}=\operatorname{Im}\left\{\Phi_{i} B\right\} \quad, \forall i \geq 0
$$

$$
\text { with } \Phi_{i}=\left[\begin{array}{c}
\underline{C}_{1} \\
\underline{C}_{2} \\
\vdots \\
\underline{c}_{i j}
\end{array}\right] \quad, \forall \mathrm{i} \geq 0
$$

Thus, we have to show that (5.14) implies (5.15). This can also be sketched through the first steps of the algorithms.

Consider the operator :[ $\left.\underline{C}_{1} A \vdots\left[C_{1} B \vdots c_{1} E\right]\right]$. Since $\underline{C}_{1} B$ is a sub-matrix of $\left[c_{1} B\right.$ : $\left.C_{1} E\right]$ and due to (5.14) (for $i=2$ ), the row compression on $\left[C_{1} B \vdots C_{1} E\right]$ say $S_{e 1}$ (see (3.3)) must be equal to $S_{1}$. Otherwise said, $C_{1} E$ cannot bring more independent rows than $\mathrm{C}_{1} \mathrm{~B}$ because of (5.14). This means that necessarily :

$$
S_{1}\left[\underline{C}_{1} A \vdots\left[C_{1} B \vdots C_{1} E\right]\right]=\left[\begin{array}{ll:l}
C_{2} \vdots D_{2} \vdots D_{2}^{\prime} \\
C_{2}: 0 & 0
\end{array}\right]
$$

and hence :

$$
\operatorname{Im}\left(\underline{C}_{1}[B: E]\right)=\operatorname{Im}\left(\underline{C}_{1} B\right)
$$

The situation is the same for the next step. Using (5.14) for $i=3$, we necessarily have :

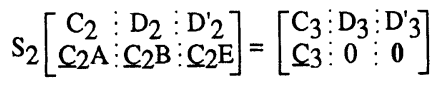

wich implies :

$$
\operatorname{Im}\left[\begin{array}{l}
\underline{C}_{1}[B: E] \\
\underline{C}_{2}[B: E]
\end{array}\right]=\operatorname{Im}\left[\begin{array}{l}
\underline{C}_{1} B \\
\underline{C}_{2} B
\end{array}\right]
$$

This is true at any step (since (5.14) holds for any $i \geq 0$ ) and thus (5.15) is established :

$\operatorname{Im}\left\{\Phi_{i}[B: E]\right\}=\operatorname{Im}\left\{\Phi_{i} B\right\} \quad, \forall i \geq 0 \quad$, which ends the proof of Theorem 2

Other interesting results can also be established with the help of this concept of zeros at infinity.

Proposition 3 For any system like (1), the rank $r(r \leq \inf (p, m))$ satisfies : $\mathrm{r}=\operatorname{dim}\left\{\operatorname{Im} \mathrm{B} /\left(\operatorname{Im} \mathrm{B} \cap \mathcal{V}^{*}\right)\right\}=\operatorname{dim}\left(\mathrm{C}^{*}\right)$

This is obvious from the fact that $r$ is the number of zeros at infinity, that is $r=p_{1}$ in Theorem $1 \bullet \cdot$

Proposition 4 System like (1) with $\mathrm{p}<\mathrm{m}$ (more inputs $(\mathrm{m})$ than outputs (p)) is never ideally observable .

Proof : Ideal observability is equivalent to $\mathcal{V}^{*}=0$ (see [2] for definition and details). If $\mathrm{p}<\mathrm{m}$, then the system is not left invertible and thus cannot be observable with unknown input. Indeed, from Proposition $3, r=p<m$ implies $\operatorname{Im} B \cap \mathcal{V}^{*} \neq 0$ and thus $\mathcal{q}^{*} \neq 0$. 
This is a generalization of a pathology enhanced in [2].

\section{6- Conclusion}

We have shown that structural concepts like zeros at infinity can be extended to some classes of infinite dimensional systems (Theorem 1) and used to solve some control problems (Theorem 2). Of course our hypothesis are somewhat restrictive : A is bounded and the number of inputs, outputs and disturbances is finite. This extension must be viewed as a first attempt to illustrate the importance of structural knowledge also in the case of infinite dimensional systems. These assumptions have to be weakened and we have many reasons to hope that some concepts and results will still be available in the same form. This comes from the fact that this particular structure must be, in some sense, independent on the way we describe a system through a model (linear or non linear, explicit or implicit, finite dimensional or not).

Aknowledgement : We would like to thank the anonymous referee who suggested the simpler present proof for the necessity part of Theorem 2 .

\section{References}

[ 1] Basile G., Marro G. 1969, " Controlled and conditionned invariant subspaces in linear system theory ", J. of Opt. Theory \& Applic., Vol. 3, n 5, pp. 306-315

[ 2] Barigou A. \& Rabah R. 1986," Observabilité idéale dans les espaces de Hilbert", A.P.I.I., Vol. 20, pp. 119-128

[ 3] Commault C., Dion J.M., Descusse J., Lafay J.F., Malabre M. 1986, "Influence de la struture à l'infini des systèmes linéaires sur la résolution de problèmes de commande", A.P.I.I., Vol. 20, n 3, pp. 207-252

[ 4] Curtain R. 1986, "Invariance concepts in infinite dimensions", SIAM J. of Control \& Optimization, Vol. 24, pp. 1009-1031

[ 5] Descusse J., Lafay J.F., Malabre M. 1983, "On the structure at infinity of linear block-decouplable systems : the general case", IEEE Trans. Automatic Control, AC-28, $\mathrm{n}^{\circ} 12$, pp. 1115-1118

[ 6] Dion J.M. 1983, "Feedback block decoupling and infinite structure of linear systems", INT. J. Control, Vol. 3, n 7 , pp. 521-533

[ 7] Lewis F., Beauchamp G. 1987, " Computation of subspaces for singular systems", MTNS'87, Phoenix, AZ, June

[ 8] Malabre M. 1982, "Structure à l'infini des triplets invariants. Application à la poursuite parfaite de modèle", 5 ème Conférence Internationale sur l'Analyse et l'Optimisation des Systèmes, INRIA, Versailles, Déc. 1982, Springer Verlag, Lecture Notes in Control and Information Sciences, Vol. 44, pp. 43-53

[ 9] Malabre M. 1985, "Sur le rôle de la structure à l'infini et des sous-espaces presque invariants dans la résolution de problèmes de commande", Thèse Doctorat ès Sciences, ENSM, Université de Nantes, March 25

[10] Malabre M. 1989, "On infinite zeros for generalized linear systems", MTNS'89, June 19-23, Amsterdam

[11] Moog C. 1987, " Inversion, découplage, poursuite de modèle des systèmes non linéaires"Thèse Doctorat ès Sciences, ENSM, Université de Nantes, May 27

[12] Silverman L.M. 1969, "Inversion of multivariable linear systems", IEEE Trans. on Automatic Control, AC-14, ${ }^{\circ} 3$, pp. 270-276

[13] Silverman L.M., Kitapçi A. 1982, "System structure at infinity", Colloque National CNRS, Développement et utilisation d'Outils et Modèles Mathématiques en Automatique, Analyse des Systèmes et Traitement du Signal, Belle-Ile, 13-18 Septembre [14] Wonham W.M. 1979, "Linear Multivariable Control : A Geometric Approach", 2 nd Edition, Applic. of Mathematics, Vol. 110, Springer Verlag, New York

[15] Zwart H.J. 1989, "Geometric theory for infinite dimensional systems", Lecture Notes in Control and Information Sciences, Vol. 115, Springer Verlag. 